Article

\title{
Perceptions of Powdered Alcohol and Intentions to Use: An Exploratory Qualitative Assessment of Potential Palcohol Use by Young Adults
}

\section{John Stogner ${ }^{1, *}$, Julie M. Baldwin ${ }^{2}$, Timothy Brown ${ }^{3}$ and Taylor Chick ${ }^{1}$}

1 Department of Criminal Justice and Criminology, University of North Carolina at Charlotte, 9201 University Boulevard., Charlotte, NC 28223, USA; E-Mail: tchick@uncc.edu

2 Department of Criminology and Criminal Justice, Missouri State University, 901 S. National Strong Hall Room. 226, Springfield, MO 65897, USA; E-Mail: JulieBaldwin@MissouriState.edu

3 Department of Criminal Justice, University of Arkansas at Little Rock, Ross Hall 5th Floor, Little Rock, AR 72204, USA; E-Mail: tcbrown2@ualr.edu

* Author to whom correspondence should be addressed; E-Mail: johnstogner@uncc.edu; Tel.: +1-704-687-8446; Fax: +1-704-687-5285.

Academic Editor: Edgar Chambers IV

Received: 14 October 2015 / Accepted: 17 November 2015 / Published: 1 December 2015

\begin{abstract}
While there seems to be growing media intrigue over atypical forms of alcohol use, the utilization of the majority of novel consumption methods (e.g., eyeballing, slimming, alcohol without liquid (AWOL)) seems minimal. In 2014, however, several outlets suggested that powdered alcohol would soon surface as a threat to public safety. The impetus of these fears was the Alcohol and Tobacco Tax and Trade Bureau's approval for Lipsmark LLC to package a powdered alcohol product named "Palcohol". Palcohol has yet to reach store shelves, but public outcry has been intense. Despite this reaction, little is known about whether the population will consider Palcohol a suitable alternative to traditional alcohol, particularly given its excessive predicted cost. In an exploratory effort to assess perceptions, use intentions, and fears related to Palcohol, 31 young adults were asked to view a 16-minute video about Palcohol and answer a series of questions about Palcohol, including whether and how they intend to use it. Results suggest that young adults intend to experiment with Palcohol following its release, but they have a number of concerns. While few expect to become habitual users of the product, many believe it will enable people to utilize alcohol in settings where its consumption is prohibited.
\end{abstract}


Keywords: powdered alcohol; Palcohol; alcohol; perceptions; planned behavior; intentions to use

\section{Introduction}

Novel alcohol consumption has consistently garnered attention from media sources over the last five years (e.g., [1,2]). While sensationalized stories of unique alcohol consumption methods such as "eyeballing", "slimming", or AWOL (alcohol without liquid) are initially met with pubic curiosity, they are often short lived with news outlets quickly turning their attention to the next and latest potential panic. The majority of these methods appear to be rarely utilized by young adults and fail to have a significant impact on public health [3] (although there appears to be growing evidence of eyeballing vodka in the United States and Europe [4]). In 2014, several media outlets turned their attention to a new threat, suggesting that powdered alcohol would soon surface as a major impediment to public health and safety. The product has yet to reach store shelves in the United States, but public outcry has been intense and led several states to proactively ban any powdered alcohol product [5].

In April 2014, reports from popular news outlets including The Washington Post, CBS News, NBC News, and the Huffington Post began to surface sensationalizing a powdered alcohol product referred to as "Palcohol" [6-9]. They described Palcohol as "the world's sneakiest and most efficient way to get drunk" [10]. Furthermore, SB Nation, a high-profile sports media blog, declared that Palcohol "promises to make game day better" [11]. The impetus of this media frenzy occurred on April 8th, 2014, when Lipsmark LLC received approval from the Alcohol and Tobacco Tax and Trade Bureau (TTB) to package their powdered alcohol product. The TTB, however, withdrew their approval two weeks later due to a discrepancy concerning how much powder will be in the package. The initial media surge subsided, but resumed with increasing furor once Lipsmark received approval for their corrected labels in March of 2015.

While sensationalized media headlines concerning Palcohol are relatively recent as is the related public outcry, powdered alcohol is not a new concept. Throughout the past 50 years, the United States Patent and Trademark Office has granted several patents for the manufacturing process of alcohol-containing powder. The Japanese company Sato Food Industries sold powdered alcohol in tablet-form as an additive. Groups in Germany and the Netherlands marketed and briefly sold a powdered form of alcohol in an attempt to bypass drinking-age laws [12]. In 2010, a U.S. company named Pulver Spirits submitted labels for a powdered alcohol product to the TTB but then withdrew the motion because of regulatory difficulties. While no recreational powdered alcohol product has ever successfully been marketed and sold in the U.S., Lipsmark has come further in the regulatory process than any other company to date.

Although Palcohol is not yet on the American market, the substantial media coverage dictates that it would be useful to anticipate the scope of interest in the product. Official data and knowledge on powdered alcohol use is limited to non-existent, but perceptions of potential users may aid in estimating expected usage rates of novel forms of substance use [13]. An assessment of perceptions is particularly important with the recent media coverage of Palcohol since media may sway user perceptions, which, in turn, could fuel the use or non-use of a drug. Social psychologists and cognitive therapists have long 
discussed the important role of perceptions on human behavior. One relevant theoretical model that deals with perceptions' effect on potential health decisions is the health belief model (HBM) [14]. The HBM is a theoretical framework for understanding why individuals make various health-related choices. Most simply, it suggests that behavior is affected by both the value an individual places on the related health goal and their estimate of the effect of the behavior under consideration on that outcome. Thus, the HBM suggests that behavior is affected by perceived susceptibility, perceived severity, perceived benefits, and perceived barriers [14]. The application of the health belief model to Palcohol use suggests that one would most likely not ingest the product if one's perception of the health and social consequences of Palcohol outweighs their perceived benefits of taking the substance. However, also according to this model, this consumption decision is also affected by the perception of barriers to the drug and cues to action. Persuasive cues to action, or reminders to engage in the positive or negative health behavior, are often found in the media [15].

The planned behavior model also acknowledges the importance of perception on one's health decisions, such as ingesting a drug. As an extension of the theory of reasoned action [16], this theory also views behavior as a rational decision-making process where attitudes, or one's beliefs about the positive or negative outcome of an action, are central components within behavioral choices. In addition, one's perceived behavioral control (perceptions of the difficulty or self-efficacy in engaging in the behavior) can potentially provide a barrier or passageway to the behavior [17]. Thus, media amplification may create the perception of ease of use due to excessive availability, potentially lowering one's perceived behavioral control that may have limited consumption of the novel alcohol.

The learning of these perceptions or normative definitions that either encourage or discourage deviant behavior has long been argued by social scientists to be heavily dependent upon social interaction [18]. It is posited that through interaction with significant others one will learn definitions either favorable or non-favorable to deviance that will play crucial roles in their decision process. Burgess and Akers [19] later added the concept of operant conditioning to Sutherland and Cressey's thesis stating that individuals also balance the anticipated punishments or rewards of the questioned behavior. More specifically, ones decision to consume Palcohol would be reinforced by perceptions of more rewarding consequences of the behavior along with the learning of more positive or neutralizing definitions of Palcohol consumption [20].

While individual perceptions of Palcohol are not readily available, the legislative backlash to the proposed drug indicates that Palcohol is perceived to be a serious health concern. The reaction to Palcohol has been intense with 31 states taking some form of direct action in response to the TTB approval of Palcohol labels. Twenty-five of these states have passed legislation banning the sale of powdered alcohol as of August 2015. Two states have placed temporary bans until further inquiry and research have been conducted. An additional four states have amended their definitions of alcohol to include powder so that it can be traditionally regulated along with liquid alcohol. All of these actions have been taken prior to any empirical indications of public interest in Palcohol [5].

The purpose of this study is to gain a preliminary understanding of the public's intentions to use Palcohol (both after mixing with water as intended and in novel ways) before it reaches the market. More specifically, this study is an exploratory effort to determine whether young people will experiment with or patronize Palcohol. Thirty-one young adults were asked to view a 16-minute video about Palcohol. Participants were then asked about their general reactions to the video, whether they view Palcohol as a 
potential problem, whether they would try it, and in what form. This study helps to fill the present gap in literature by helping to answer if the concerns over Palcohol are justifiable or necessary. Furthermore, this manuscript helps increase our collective knowledge of alcohol by examining what factors, such as perceptions, may fuel use, including nontraditional forms and novel consumption methods.

\section{Methods}

During July of 2015, 31 young adults were asked to view a 16 min and $42 \mathrm{~s}$ video focused on Palcohol. Within the video, the creator of Palcohol, Mark Phillips, endorses the product, demonstrates mixing the powder with water, and discusses its potential utility - suggesting among other things that it would be a useful product for hikers concerned with pack weight and airlines looking to reduce the space and weight allotted to alcohol and mixers on flights. Given Phillip's close association with the product, the video is obviously biased [21]; however, it has great utility in that it represents the style of advertising to which potential users are likely to be exposed. The study subjects, were recruited from a single class at a major University in the Southeastern United States. Potential participants were informed that "Participation in this study is entirely voluntary and will not impact your performance in this class.", of the 31 participants, 12 were male and 19 were female. No other identifying information (specific age, race, etc.) was recorded. After watching the video, participants were then individually asked a series of open-ended questions about their views on the product and intent to use Palcohol once it reached store shelves in the local area. Their responses both offer insight into which portions of the Palcohol "pitch" young people will accept and whether similarly situated young adults will experiment with Palcohol (IRB Protocol \#15-06-11).

\section{Results}

When asked "Would you try it?", over half of the respondents $(54 \%)^{1}$ mentioned in their responses that they would try Palcohol once it became available in the area. This is an overwhelming majority of alcohol users considering that at least three of the respondents were not current consumers of alcohol in its more traditional forms (although the responses of two of these three suggested past alcohol use). Willingness to consume Palcohol did not seem to be contingent on gender as $60 \%$ of males and $50 \%$ of females offering a firm answer to the question stated that they would try Palcohol. Some respondents were quite excited about the product and its novelty:

"I would definitely try it. It's a great idea. I believe a lot of people would love to try this and there definitely is a big market for it. I am curious to see how it tastes and how effective the drink itself will be. I think it's a cool idea and I would love to try it." (Participant \#5, male)

"I would definitely try it. It has a cool package and I think it's cool that you are really making your own drink and you don’t even need glasses." (Participant \#9, male)

However, most affirmative responses were subdued after being asked "When would you try Palcohol? How? Why?" These respondents mentioned they would try Palcohol but that they would not go out of

\footnotetext{
${ }^{1}$ Not all respondents directly addressed each question. Therefore, some of the indicated percentages are for fewer than 31 respondents.
} 
their way to purchase it. They indicated an interest in experimentation if the situation presented itself, but that their use would be limited.

"I would try it. I would not purposely go and find it, but if it is available to me from a friend or anything like that then I would definitely want to try it." (Participant \#7, female)

"I would probably try it once, but I don't really get the point of it. If I'm going to drink alcohol, I can drink it just as easily out of a bottle. (Participant \#17, female)

As might be expected, some respondents were strongly opposed to Palcohol and denied interest in experimentation. They cited numerous reasons ranging from abstaining from alcohol more generally to issues of taste and cost. Interestingly, only one questioned the safety of the product and suggested that he would avoid Palcohol because it may be harmful. This respondent was also concerned with cost: "I myself would not try it because, if it is only equal to one shot, I would be wasting my money" (Participant \#21, male). Aside from abstainers, the most common reasons for intending to avoid the product was the expectation that it would not fully dissolve in water and that it would not taste good.

"Powdered drinks are normally not as appetizing as a normal liquid drink because they seem to be gritty and not fully mixed." (Participant \#3, female)

"The thought of the powder-That's a huge bag! — Grosses me out." (Participant \#4, female)

"When I enjoy an alcoholic beverage it is because I actually enjoy the taste of the beverage.

It is hard for me to imagine that Palcohol could taste that great, especially after his display of how long it takes to get it to dissolve in water." (Participant \#16, female)

"For me, I do not like powdered substances and I would feel like mixing that within a soda or other liquid, the Palcohol would not dissolve completely." (Participant \#23, female)

A common theme in the answers of those respondents that did intend to try Palcohol was curiosity. Most of these respondents seemed more intrigued by the product's novelty than drawn to its potential utility. A number of responses directly mentioned curiosity while others implied that it would be the motivation for their use:

"I can see myself definitely trying Palcohol, just because of curiosity of the taste." (Participant \#10, female)

"The reason I want to try it is to see if it actually has the same effects as alcohol and if it remotely taste the same as the drinks it is supposed to represent." (Participant \#12, male)

"I would try it because I have previously tried alcohol in its normal liquid form and would be curious to see if it tastes the same as its normal drink" (Participant \#24, female)

Additionally, several who stated they would try Palcohol indicated that they would do so with friends or in a social setting.

"I would probably try it in a social setting with friends because I imagine they would be interested in it also." (Participant \#6, male)

"I feel that this would be something I would consider trying with friends in a social setting." (Participant \#2, female) 
"I would use it for a social thing to do, like 'hey guys, you want to make some alcohol tonight? I got some alcohol."” (Participant \#9, male)

None of the respondents mentioned using Palcohol for its intended purposes (i.e., on hiking trips or flights). "Personally, after I hike, the only thing I typically want to drink is water so it wouldn't be beneficial in that situation for me either" (Participant \#17, female). Similarly, very few mentioned that they would personally sneak Palcohol into an activity where it was banned (e.g., sporting event, movie) as has been suggested by the media. Respondents did suggest that they may use Palcohol in bars and clubs to avoid long waits for drinks. For example, "It's better than waiting on someone to make you a drink" (Participant \#13, male). This potential misuse of Palcohol has not been described to our knowledge in any reports, attesting to the resourcefulness of young substance users. Respondents only reported that they themselves would use Palcohol as intended: "I wouldn't abuse it and snort it or swallow it by any means" (Participant \#13, male).

Respondents were also asked a series of questions about whether they perceived Palcohol would become a major issue ("Do you think Palcohol will become problematic in the United States?"; "Why?"; "What kind of problems?") and how they thought it should be regulated ("Should it be allowed to be sold?"; "Where?"). Over two-thirds (68\%) believed that Palcohol was a product that should be allowed to reach store shelves; however, virtually all of these respondents suggested that since the product was akin to liquor that it should be sold only in ABC stores (the state in which data was collected only allows liquor sales through stores operated by local alcoholic beverage control (ABC) boards). These respondents seemed to support Lipsmark's right to market Palcohol either because they were interested in experimenting with the substance or because they favored the traditional approach to substance use regulation. That being said, after being asked "What do you think about the Palcohol founder's pitch?", a small number were vehemently opposed to Palcohol's marketing ("I do not think this product should be sold anywhere" (Participant \#18, female)).

Respondents were more open about the alternative techniques that may be used to administer Palcohol when asked general questions rather than ones specific to their own intended use. Though none mentioned snorting the powder when asked about their own intentions, many did so when mentioning the "dangers" related to Palcohol. Perhaps they believed others would make riskier choices than themselves; alternatively, they may have had reservations admitting that they were considering ingesting the product in a way that would be more stigmatizing. Regardless, insufflation and intravenous injection were mentioned by multiple respondents:

"People would be tempted to try snorting it, especially if they are drunk." (Participant \#8, male)

"The largest potential problem I see is the risk that people will snort the substance." (Participant \#16, female)

"I think that people will start to get the idea to start snorting Palcohol and injecting it intravenously which is probably very dangerous." (Participant \#18, female)

One respondent noted a potential ramification of Palcohol that was not foreseen. He suggested that young people might be willing to insufflate Palcohol due to their experiences with liquid alcohol that, in turn, would create familiarity with this route of substance administration. Though insufflation is not a 
technique that requires skill or practice, the notion that familiarity with it may lessen apprehension about insufflating other drugs is intriguing:

"Snorting would be very painful and could result in permanent damage as well as a teaching method for snorting cocaine." (Participant \#4, female)

While few respondents had mentioned any intent to sneak Palcohol into areas where alcohol use was restricted, many thought that their peers would. They seemed to believe that it would be easier to conceal than alcohol in other forms:

"Smuggling alcohol into places where it is prohibited is already not the hardest thing to do, but it will be a lot easier with a powdered substance. A small pouch is much more discreet than glass bottles, or even water bottles filled with liquor." (Participant \#2, female)

"It would be easy to take into a concert, movies, school and sporting events and just pour it in a water bottle, leading to illegally taking it into places that prohibit outside drinks." (Participant \#13, male)

"What stops people from bringing powder anywhere they go? And what is stopping them from drinking at school? Theaters? Work? Literally anywhere?” (Participant \#5, male)

Others offered the opposite opinion due to the size of Palcohol packets. They insinuated that Palcohol would be more challenging to sneak past checkpoints since it is physically larger than a miniature alcohol ("airplane") bottle. One respondent claimed that it "would be difficult and are unrealistic because Palcohol comes in a large metallic bag that would not be easy to sneak into venues" (Participant \#23, female). Another, after similarly suggesting that the size was problematic for concealing implied that the package's flat shape may assist in getting past event security. Regardless, it does seem that young people near immediately consider Palcohol a form in which allows alcohol to be more easily consumed in places where it is banned.

Responses were mixed in regard to potential for Palcohol to be used in criminal activity. Specifically, respondents differed in their belief that Palcohol could be used to alter someone's beverage without their knowledge due to the lengthy period of time required for it to fully dissolve.

"It is also a white powder that would be easily seen if tried to be used for a date rape drug." (Participant \#23, female)

"It takes almost a minute to dissolve into the water or other liquid it is being mixed with making it impractical as a date rape drug." (Participant \#16, female)

"Yes, I can see some people using it to try and spike someone's drink" (Participant \#24, female)

"It would make it unsafe for individuals because it would become easier to spike or contaminate drinks which could lead to many other problems and crimes." (Participant \#8, male)

Some believed that Palcohol would be easier for adolescents to obtain than traditional alcohol. This hypothesis is questionable given the likely expense relative to liquor, but this is an issue that warrants empirical study should Palcohol reach the market. Finally, respondents raised two other potential issues, 
neither of which was anticipated prior to the study. It was suggested that the powder would be mixed with other powdered psychoactives to alter their effects (e.g., cocaine). It was not clear whether the respondent believed users would mix their own Palcohol-drug cocktail or whether illicit substance distributers would do so. Similarly, it was not clear whether she (Participant \#26, female) believed the user would ingest or insufflate the mixture. A different respondent suggested that others may mix Palcohol with energy drinks rather than water. The combination of caffeine and alcohol has been considered dangerous, leading to some formulations (e.g., the original "Four Loko" product) being removed from store shelves. However, it is not clear whether the respondent is correct in that "mixing it with an energy drink could amplify the effects" (Participant \#21, male) or whether Palcohol would even dissolve in an energy drink. Overwhelmingly, respondents felt that the form of alcohol is inconsequential for use and risks. The majority of respondents viewed Palcohol as no different than traditional liquid alcohol in regard to risks and anticipated use:

"People who use Palcohol are going to have the same issues as people who drink already prepared alcohol.” (Participant \#9, male)

"I don't believe Palcohol will be any more problematic in the United States than that of regular alcohol. I think the reason for this is because Palcohol is the same thing as regular alcohol; it's just in the powder form." (Participant \#6, male)

\section{Discussion and Conclusion}

While Palcohol is neither currently available for purchase nor may ever be in the future, perceptions regarding powdered alcohol are worthy of study. As media outlets may take actions resulting in the formation of drug scares [22], academic inquiry is necessary to balance potentially sensationalized concerned and presenting a clear picture of potential harms. Examinations attempting to understand the public's intentions regarding use are necessary; further, their results must be publicized in an effort to combat the emergence of an unfounded contemporary drug panic. Drug panics, while often volatile like other moral crusades, can often lead to costly allocation of resources to combat certain behaviors that may not be a threat in the real world [23]. For example, prior to this study, it was completely unknown whether media concerns over Palcohol were justifiable due to the absence of any research on the subject. However, regardless of a lack of research, understanding of public opinion, or an objective assessment of actual health dangers posed by Palcohol, 27 states proactively passed legislative or temporary bans on the sale of powdered alcohol [5].

Results from this preliminary study suggest that widespread concern and resources necessary for its prohibition may not be warranted, although many states have already expended time and energy on this. Respondents clearly indicated a willingness to experiment with Pacohol, but similarly clearly expressed loyalty for traditional alcohol. Respondents do not intend to repeatedly use the substance if it becomes available; curiosity seemed to be the driving interest. The majority of this study's respondents supported Palcohol being regulated and sold in a similar manner as liquid alcohol, yet only four states amended current legislation to regulate powdered alcohol the same as liquid alcohol. Relatedly, understanding potential voters views on powdered alcohol may have political benefit in terms of candidates both wanting to accurately represent their constituents and attempting to increase voter support for themselves. 
Additionally, understanding potential users' perceptions of Palcohol allows for a preliminary estimation of how popular Palcohol use may actually be if marketed to the public. Specifically, incorporating this study's findings on attitudes and perceived side effects, benefits, and barriers into the health belief, planned behavior, and differential-reinforcement models provides preliminary popularity estimates for Palcohol. Perceptions of severe side effects were either exactly the same as those associated with liquid alcohol or were slightly higher when respondents mentioned novel consumption methods, such as insufflation of the powdered substance. However, benefits or positive outcomes related to Palcohol use were not widely perceived. Based on these findings, Palcohol use can be expected to be low due to indiviudal's rational calculus that the anticipated negatives outweigh positives of Palcohol relative to traditional alcohol.

Overall, the perceptions of barriers were mixed as some saw the ease and a variety of purposes of use, while others viewed utilizing Palcohol as expensive, cumbersome, and requiring too much effort. These competing views do not indicate an overwhelming popularity for the substance. While difficulty obtaining Palcohol is unknown because it is not available, many recommended that it be available to those of legal drinking age from traditional alcohol retailers. If sale is regulated in this fashion, this availability to interested consumers of legal age may increase popularity. However, this effect may vary by jurisdiction as liquid alcohol is more difficult to obtain in some jurisdations ("dry counties" versus "wet counties"). Furthermore, these consumers may still purchase traditional alcohol instead of its powdered competitor due to perceptions of similar negative but lower positive outcomes of the product paired with increased financial cost. Finally, many responses included a social aspect, which can be discussed in relation to both social learning and the health belief model's cues to action. If individuals believe that socially consuming Palcohol is fun and normal and is favored by their peers, these beliefs may increase their likelihood of buying and using it.

It is important to note that: (1) perceptions of peer behavior, including deviance, have been determined to be correlates of one's own behavior [24] and (2) one's perceptions of his/her peers behavior does not always coincide with the peers' actual behavior. ${ }^{2}$ These facts may be of extreme interest to the media as it has the potential to portray specific behaviors, such as Palcohol use, as highly accepted and beneficial through the respective portrayal of many individuals consuming Palcohol while having fun and not experiencing negative side effects. As previously mentioned in the health belief model, the media often utilizes persuasive cues to action that affect human behavior. In an effort to increase the popularity of Palcohol, these tactics may sway the current preliminary mixed attitudes of potential users by highlighting the social use of Palcohol. Conversely, negative effects of alcohol and conveying social stigmatization may reduce the likelihood of patronage. For instance, research has found that the stigmatization associated with crack has eschewed the use of the drug by young adults even within environments that would usually put them at risk for drug abuse [28].

While the present exploratory study offers the first insight into potential users perceptions of powdered alcohol, it is not without limitations. First, the sample was only comprised of young adults

2 One's perception of his/her peers behaviors has traditionally only been measured by focusing on that individual's perceptions (e.g., [25]), which is referred to as a "perceptual" or "indirect" measure as it focuses solely on perceptions of others and not their actual behavior [26]. Recent research has begun to examine and compare both indirect and direct measures of peer deviance (e.g., see [27]). 
enrolled in higher education in an area with relatively prohibative substance use regulation. Palcohol may be more appealing to those who are less educated or have yet to reach adulthood. It is imperative that future research explore the attitudes and motivations specific to Palcohol held by those under the legal age. They may be differentially willing to experiment with and use powdered alcohol given the challenges they face in aquiring and storing liquid alcohol. Similarly, perceptions of Palcohol may be more negative in areas where attitudes toward alcohol use, and even marijuana use, are more permissive due to it seemingly being relatively less desireable. The sample was not large enough nor randomly selected which prevents generalization of findings to the broader population, but this qualitative inquiry was able to draw detailed information from a sufficient number of individuals to suggest that more research on the subject is warranted.

Given the emergence of other novel forms of drug use and administration [29-31], future research should examine a variety of elements regarding Palcohol and powdered alcohol, in general. In particular, additional studies should explore interest in, and concerns regarding, powdered alcohol use and misuse in larger and more diverse samples to determine whether this study's findings are nationally representative. Research should also explore novel use and risks associated with consumption of powdered alcohol in countries where it is currently available. This course of study would provide insight into dangers that could potentially emerge in the U.S. if Palcohol was made available for sale. Studies, utilizing a variety of health promoting advertisements and constructed similar to the National Survey on Parents and Youth, can aim to determine which aspects of Palcohol can be emphasized to positively affect the health-related behaviors of young adults. More importantly, there is an evident need for research on the health consequences both of ingesting Palcohol as intended and in alternative ways that are not recommended by its manufacturer.

\section{Author Contributions}

Stogner and Chick initiated the study and collected data. Stogner oversaw the development of this manuscript and authored the results section. Baldwin authored the discussion section and Brown authored the introduction/literature review. Chick gathered literature, investigated the legal status of powdered alcohol products, and created an initial draft. All authors edited the complete manuscript and approved its final form.

\section{Conflicts of Interest}

The authors declare no conflict of interest.

\section{References}

1. Sifferlin, A. Smoking Alcohol: The Dangerous Way People Are Getting Drunk. Available online: http://healthland.time.com/2013/06/05/smoking-alcohol-the-dangerous-way-people-are-gettingdrunk/ (accessed on 7 December 2013).

2. Hickman, H. Alcohol 'enema' Sends Student to ER; Fraternity Chapter Suspended. Available online: http://www.knoxnews.com/news/2012/sep/24/ut-fraternity-suspended-over-graphic-alcohol/ (accessed on 6 December 2013). 
3. Stogner, J.M.; Eassey, J.M.; Baldwin, J.M.; Miller, B.L. Innovative alcohol use: Assessing the prevalence of alcohol without liquid and other non-oral routes of alcohol administration. Drug Alcohol Depend. 2014, 142, 74-78.

4. Bersani, F.S.; Corazza, O.; Albano, G.; Bruschi, S.; Minichino, A.; Vicinanza, R.; Bersani, G.; Martinotti, G.; Schifano, F. The "Eyeballing" technique: An emerging and alerting trend of alcohol misuse. Eur. Rev. Med. Pharmacol. Sci. 2015, 19, 2311-2317.

5. Naimi, T.S.; Mosher, J.F. Powdered alcohol products: New challenge in an era of needed regulation. JAMA 2015, 314, 119-120.

6. Firger, J. Palcohol Powdered Alcohol may Present Serious Health Risks, Experts Say. Available online: http://www.cbsnews.com/news/palcohol-powdered-alcohol-may-present-serious-health-risks/ (accessed on 24 September 2015).

7. McCormack, S. Powdered Alcohol Has Arrived. Available online: http://www.huffingtonpost.com/ 2014/04/21/powdered-alcohol-palcohol_n_5185944.html (accessed on 24 September 2015).

8. McCue, L. Powdered Alcohol Is a Real Thing and We're not Sure Why. Available online: https:/www.washingtonpost.com/express/wp/2014/04/20/powdered-alcohol-palcohol/pow (accessed on 24 September 2015).

9. Parker, L.; Green R. Health Officials Raise Concerns of "Palcohol". Available online: http://www.nbcchicago.com/investigations/Health-Officials-Raise-Concerns-Over-Palcohol-286167311.html (accessed on 24 September 2015).

10. Murphy, M. Powdered Alcohol, Coming to a Liquor Store Near You. Available online: http://gawker.com/powdered-alcohol-coming-to-a-liquor-store-near-you-1565094422 (accessed on 24 September 2015).

11. Dator, James. Powdered Alcohol is a Thing, Promises to Make Game Day Better Available online: http:/www.sbnation.com/lookit/2014/4/18/5628342/powdered-alcohol-is-a-thing-promises-tomake-game-day-better (accessed on 24 September 2015).

12. National Alcohol Beverage Control Association (NABCA). Powdered Alcohol: An Encapsulation. Available online: http://www.nabca.org/assets/Docs/Research/Studies/Powdered_Alcohol_Paper_ Dec_2014\%282\%29.pdf (accessed on 8 October 2015).

13. Stogner, J.M. Predictions instead of panics: The framework and utility of systematic forecasting of novel psychoactive drug trends. Am. J. Drug Alcohol Abuse 2015, 41, 519-526.

14. Hochbaum, G.; Rosenstock, I.; Kegels, S. Health Belief Model. Available online: http://www.infosihat.gov.my/infosihat/artikelHP/bahanrujukan/HE_DAN_TEORI/PDF/Health\% 20Belief\%20Model.pdf (accessed on 25 June 2015).

15. Gerend, M.A.; Shepherd, J.E. Predicting human papillomavirus vaccine uptake in young adult women: Comparing the health belief model and theory of planned behavior. Ann. Behav. Med. 2012, 44, 171-180.

16. Fishbein, M.; Ajzen, I. Belief, Attitude, Intention and Behavior: An Introduction to Theory and Research; Addison-Wesley Publishing Company: Reading, MA, USA, 1975.

17. Ajzen I. The theory of planned behavior. Organ. Behav. Hum. Decis. Process. 1991, 50, 179-211.

18. Sutherland, E.H.; Cressey D.R. Principles of Criminology, 4th ed.; J.B. Lippincott Co.: Philadelphia, PA, USA, 1947. 
19. Burgess, R.L.; Akers, R.L. A differential association-reinforcement theory of criminal behavior. Soc. Probl. 1966, 14, 128-147.

20. Akers, R.L.; La Greca, A.J.; Cochran, J.; Sellers, C. Social learning theory and alcohol behavior among the elderly. Sociol. Q. 1989, 30, 625-638.

21. The Truth about Palcohol. Available online: https://www.youtube.com/watch?v=LYP085QJvtk (accessed on 25 June 2015).

22. Reinarman, C.; Levine, H.G. Crack in context: Politics and media in the making of a drug scare. Contemp. Drug Probl. 1989, 16, 535-577.

23. Goode, E.; Ben-Yehuda, N. Moral panics: Culture, politics, and social construction. Ann. Rev. Sociol. 1994, 20, 149-171.

24. Akers, R.L. Social Learning and Social Structure: A General Theory of Crime and Deviance; Transaction Publishers: New Brunswick, NJ, USA, 2009.

25. Elliott, D.S.; Huizinga, D.; Ageton, S. Explaining Delinquency and Drug Use; Sage: Beverly Hills, CA, USA, 1985.

26. Weerman, F.M.; Smeenk, W.H. Peer similarity in delinquency for different types of friends: A comparison using two different measurement methods. Criminology 2005. 43, 499-523.

27. Boman, J.H; Young, J.T.N.; Baldwin, J.M.; Meldrum, R.C. Specifying the sources of misperceptions of peer deviance: A tale of two levels. Crim. Justice Behav. 2014, 41, 91-113.

28. Furst, R.T.; Johnson, B.D.; Dunlap, E.; Curtis, R. The stigmatized image of the "crack head": A sociocultural exploration of a barrier to cocaine smoking among a cohort of youth in New York City. Deviant Behav. 1999, 20, 153-181.

29. Khey, D.N.; Stogner, J.M.; Miller, B.L. Emerging Trends in Drug Use and Distribution; Springer International Publishing: Boston, MA, USA, 2014.

30. Stogner, J.M.; Baldwin, J.M.; Eassey, J.M.; Miller, B.L. Promoting pragmatism over panic: The case of alcohol inhalation and other nontraditional forms of alcohol use. J. Stud. Alcohol Drugs 2014, 75, 719-720.

31. Stogner, J.M; The potential threat of acetyl fentanyl: Legal issues, contaminated heroin, and acetyl fentanyl "disguised" as other opioids. Ann. Emerg. Med. 2014, 64, 637-639.

(C) 2015 by the authors; licensee MDPI, Basel, Switzerland. This article is an open access article distributed under the terms and conditions of the Creative Commons Attribution license (http://creativecommons.org/licenses/by/4.0/). 